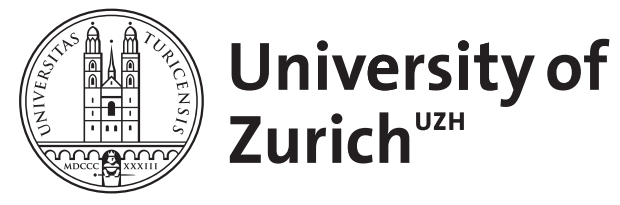

Zurich Open Repository and Archive

University of Zurich

University Library

Strickhofstrasse 39

CH-8057 Zurich

www.zora.uzh.ch

Year: 2018

Commutative justice and access and benefit sharing for genetic resources

Deplazes-Zemp, Anna

DOI: https://doi.org/10.1080/21550085.2018.1448042

Posted at the Zurich Open Repository and Archive, University of Zurich

ZORA URL: https://doi.org/10.5167/uzh-160847

Journal Article

Originally published at:

Deplazes-Zemp, Anna (2018). Commutative justice and access and benefit sharing for genetic resources. Ethics, Policy Environment, 21(1):110-126.

DOI: https://doi.org/10.1080/21550085.2018.1448042 
This article was publishes as: Deplazes-Zemp, Anna. 2018. "Commutative Justice and Access and Benefit Sharing for Genetic Resources" Ethics, Policy \& Environment. doi:10.1080/21550085.2018.1448042

\title{
Commutative Justice and Access and Benefit Sharing for Genetic
} Resources

Anna Deplazes-Zemp

Centre for Ethics, University of Zurich, Zurich, Switzerland

Zollikerstr. 117

8008 Zurich

(+41446348534)

deplazes@ethik.uzh.ch

\section{Keywords}

Access and benefit sharing, commutative justice, Convention on Biological Diversity, genetic resources, natural resources

\section{Commutative Justice and Access and Benefit Sharing for Genetic Resources}

\author{
Abstract \\ The Convention on Biological Diversity (CBD) and its Nagoya Protocol (NP) \\ established an Access and Benefit Sharing (ABS) system between utilizers and \\ providers of genetic resources. ABS is understood as a tool that should promote \\ commutative justice between the involved parties. This essay discusses what \\ exactly it is that is being exchanged in the ABS process. It critically analyses moral \\ claims to compensation that are implied by the ABS system for genetic resources. \\ It argues that with the exception of cases in which traditional knowledge is \\ involved, states are not automatically entitled to compensation in return for the \\ utilization of genetic resources growing within their territory. However, \\ biodiversity-rich states that make an effort to protect biodiversity must be \\ compensated for complying with the requests set out in the CBD. Although it \\ acknowledges that the NP is a step towards recognizing this claim, this essay \\ argues that ABS is not the appropriate method to compensate for biodiversity \\ conservation.
}




\section{Introduction}

It is a declared aim of the international community to achieve fair and equitable sharing of benefits from the utilization of genetic resources. This was recorded as the third objective of the UN Convention on Biological Diversity (CBD) (UN, 1992) and specified in the "Nagoya Protocol on Access to Genetic Resources and the Fair and Equitable Sharing of Benefits Arising from their Utilization" (NP) (UN, 2010). International law thus tells us that states which provide access to genetic resources have legal claims to a share of the benefits derived from their utilization. Ethical reflections on this idea of fair and equitable access and benefit sharing (ABS) often indicate that it is considered to be an instrument of compensation which should promote justice in the sense of commutative justice or justice in exchange (Dauda \& Dierickx, 2013; De Jonge, 2011; De Jonge \& Korthals, 2006; Korthals \& De Jonge, 2009; Schroeder, 2007; Schroeder \& Pisupati, 2010; Stumpf, 2014). All of these theorists have added that it is insufficient to evaluate ABS exclusively from the point of view of commutative justice but that other dimensions of justice must be considered too. Nevertheless, this essay will focus on the commutative justice aspect because the function of ABS to promote this type of justice is usually taken for granted without further scrutiny. The aim of this study is to clarify exactly what is being exchanged in the context of ABS and what compensation claims are being implied. This is not only an important point for theoretical discussion but also for the future implementation of ABS in domestic legislation. As an ethical reflection on the CBD and the NP this essay critically examines the moral rather than legal arguments that are implied by the ABS system. For this purpose, it examines three questions: First, what moral claims to a share of the benefits, from the utilization of genetic resources, are implied by ABS in the CBD and NP; second, to what extend can these claims be morally justified with reference to commutative justice; and third, is this system a fair means to deal with justified compensation claims by biodiversity-rich states? The essay starts with some introductory information on the CBD and the NP. This is followed by a brief introduction to the concept of commutative justice and an initial overview of moral claims to genetic resources as they are implied in the text of and discussions on the CBD and the NP. In the subsequent sections, these claims are examined in more detail. For each claim a brief scenario exemplifies the type of exchange concerned and illustrates what commutative justice requests have been implied. After a brief excursion to review some related arguments from other domains of justice, the essay closes with a 
conclusion section that entails three recommendations on how the arguments of this analysis could be considered in the practical implementation of ABS.

\section{The Convention on Biological Diversity (CBD) and its Nagoya Protocol (NP)}

The growing awareness for environmental issues and commitment to sustainable development in the second half of the $20^{\text {th }}$ century led to the seminal Rio Earth Summit in 1992. At this conference, the CBD was opened for signature. It was ratified or accepted by some 190 states and entered into force on 29 December 1993. ${ }^{1}$ The CBD addresses the problem of the extinction of species in a world divided between industrialized biodiversity-poor states and developing biodiversity-rich states through three objectives: 1. "The conservation of biological diversity," 2. "The sustainable use of its components," 3. "The fair and equitable sharing of the benefits arising out of the utilization of genetic resources [...]" (CBD Article 1). ${ }^{2}$ The third objective of the CBD is specified in its article 15. The first paragraph of this article says: "Recognizing the sovereign rights of States over their natural resources, the authority to determine access to genetic resources rests with the national governments." Thus, researchers or industry representatives who desire to use genetic resources must contact the providing state. Furthermore, they must inform the providing state about the project and get permission in the form of prior informed consent (PIC) to access the genetic resource (CBD article 15.5). Moreover, they must share benefits and profits resulting from the utilisation of genetic resources with the providing state according to mutually agreed terms (MAT) in a fair and equitable way (CBD articles 15, 19). In turn, article 15 of the CBD also specifies that biodiversity-rich providing states should make an effort to facilitate access to genetic resources for "environmentally sound uses."

Developing states have criticized the slow implementation of the third CBD objective of fair and equitable benefit sharing. As a result, after long and difficult discussions that took place over several years, a protocol that provides a more specific regulatory framework for ABS was adopted by the parties to the CBD at their tenth meeting in Nagoya in October 2010 (Buck \& Hamilton, 2011). This was the NP, which

\footnotetext{
1 For more information see CBD-website: http://www.cbd.int/history/, http://www.cbd.int/information/parties.shtml\#tab=1 (accessed Sept 2016)

2 Because genetic resources in the CBD and NP are discussed in the context of biodiversity conservation, the evident objects are various types of plants, animals and microorganisms living in the natural environment of humans. In the official Decision X/1, in which the Conference of the Parties of the CBD adopted the NP, the parties explicitly state in a comment that human genetic resources should not be subject to the NP (Greiber et al., 2012: pp.71, 362).
} 
entered into force in October 2014. The framework outlined by the NP should be implemented into the domestic legislation of all member states. The NP attracted attention for its particular consideration of indigenous and local communities. The request for dealing with traditional knowledge associated to genetic resources, which remained very vague in the CBD (CBD article 8j), has been elaborated upon in the NP. It specifies that, particularly if the use of genetic resources is coupled with traditional knowledge, users are required to implement PIC and MAT not only involving the provider state but also the concerned indigenous and local communities, which also have claims to benefit sharing (NP articles 7,12).

\section{ABS as a Tool to Promote Commutative Justice}

What are the ethical claims that underlie the idea of ABS for genetic resources as the core principle of the NP? Doris Schroeder explains that the phrase 'benefit sharing' entered international law with the CBD (Schroeder, 2006). She suggests a definition of 'benefit sharing' for this context: "Benefit-sharing is the action of giving a portion of advantages/profits derived from the use of genetic resources or traditional knowledge to the resource providers, in order to achieve justice in exchange" (Schroeder, 2007). Other authors too, have emphasized that fair and equitable benefit sharing is a question of justice in exchange, which is also known as 'commutative justice' (Dauda \& Dierickx, 2013; De Jonge, 2011; De Jonge \& Korthals, 2006; Korthals \& De Jonge, 2009). This aspect of justice concerns the exchange of items between two parties. In order to fulfil the justice criteria, the exchanged items must be equivalent (substantive aspect) and there should not be any excessive inequalities between the two parties (procedural aspect). While emphasizing the aspect of commutative justice, the authors usually refer

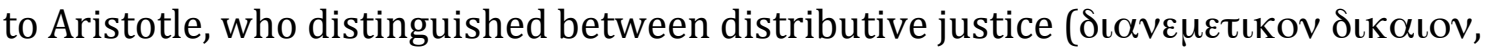

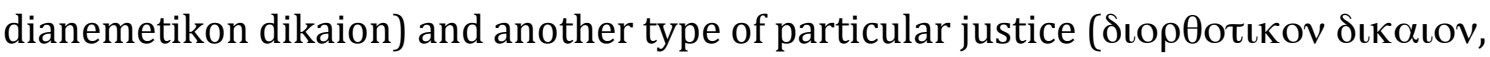
diorthotikon dikaion), which in English is usually translated as rectifying or corrective justice (Aristotle, 1992: Book V, Ritchie, 1894). Rather than speaking of two types of justice, some theorists interpret Aristotle as suggesting a threefold division of distributive, commutative and reparative justice. ${ }^{3}$ In this article, we focus on commutative justice that concerns the simultaneous exchange processes and separate it from reparative justice, dealing with compensation for injustices suffered in the past. It

\footnotetext{
${ }^{3}$ As a standard reference of different interpretations of Aristotle's understanding of the different aspects of particular justice see (Ritchie, 1894).
} 
is not surprising that commutative justice in the sense of a simultaneous exchange has been discussed as a key principle in business ethics. In the context of a market economy, this type of justice requires that each party receives the monetary equivalent of service or wares (Koslowski, 2001). However, as indicated above, there are different interpretations of commutative justice. Doris Schroeder and Balakrishna Pisupati in a UNEP Report distinguish between an Aristotelian and a Roman Law understanding of commutative justice. With the Aristotelian interpretation they refer to the substantive understanding also found in business ethics. This approach is driven by the key question of whether one side paid the proportionate compensation for what it received from the other side. In contrast, the Roman Law interpretation of commutative justice, which was favoured and applied by Schroeder and Pisupati, is based on its formal requirements, namely that both parties voluntarily agree on the conditions of the exchange procedure (Schroeder \& Pisupati, 2010). This article focuses on the substantive aspect of commutative justice. It examines exactly what is being exchanged in the ABS system. What is it that the provider countries are compensated for in the Nagoya Protocol? ABS can only serve as a tool to promote commutative justice if the compensation claims that it addresses can be justified by commutative justice. Procedural questions, such as whether indigenous peoples have been appropriately considered, are not the focus here mainly because addressing this type of question would go far beyond commutative justice. Nevertheless, the issue of justice towards indigenous and local communities will be touched upon in various contexts in this article.

The question of what it is that provider countries receive compensation for under the ABS system, will be addressed by examining four suggestions that are implicitly assumed in the text and context of the CBD and its NP. The basic structure of the related arguments is introduced using four general scenarios. In short, the scenarios are based on the following observations that will be established in more detail as the essay proceeds: The NP is often mentioned in the context of biopiracy. The idea that ABS could serve as a tool to deal with this issue is taken up by the first scenario of 'A share of benefits for active contribution'. The fact that genetic resources are discussed as a type of biological- and thus natural resource is considered by the second scenario: 'compensation for passive contribution'. A more modest interpretation of the contribution by the provider of genetic resources would speak of assistance as outlined in scenario three: 'compensation for assistance'. Finally, the integration of the ABS 
system in the CBD suggests that it may be understood as a reward for conservation of biodiversity in the sense of scenario four: 'compensation for compliance with a request'.

\section{Compensation for Active Contribution}

The NP is expected to prevent future cases of biopiracy by providing a framework in which such cases would be illegal and would thus be subject to prosecution (Kamau, Fedder, \& Winter, 2010). The biopiracy cases that are brought forward to illustrate the problem are usually examples in which large pharmaceutical companies develop profitable products based on traditional knowledge. These examples are characterized by the fact that the development of a pharmaceutical was triggered by the observation that indigenous people used the active compound in question to treat a medical condition. The cases of the Hoodia cactus and the Neem tree are amongst the most widely discussed examples of biopiracy. The Hoodia-case involves traditional knowledge of the South African San people about the appetite-suppressing effects of the Hoodia cactus (Beattie, 2005; Wynberg, 2005). In the case of the Neem tree, knowledge of indigenous Indian people about the medical benefits of this tree has been exploited (Biswas et al., 2002; Sheridan, 2005). These two biopiracy cases attracted considerable attention and were widely criticised by commentators. What kind of moral justification can explain compensation claims by indigenous communities to a share of the benefits? In the Hoodia- and Neem cases the indigenous communities actively contributed to the development of the actual or potential drugs by providing the key idea for the development of the product. Active contribution is understood in this essay as intellectual or manual participation in the production and design process. This form of contribution can be exemplified and justified using the first scenario:

Scenario one: Compensation for active contribution: People merit a share of the benefits when they actively contributed to the result or product that generated the benefits in question. If person A contributes to person B's design or production of a machine that generates a profitable product or that can be sold for a good price, A is entitled to some of these benefits because A's contribution was necessary for the success of the product. Moreover, the fact that B used A's idea makes it much more difficult for A to use the idea herself. The extent of this claim depends on the contribution and the condition under which A's work has been used. This entitlement is the basic argument for a patent system according 
to which person B must pay royalties to person A if B uses A's work for which A has a patent.

The intellectual property right system thus rewards active contributions in the sense of innovation. However, traditional knowledge cannot be protected by the classical patent system, because patents are usually granted for novel inventions and they are valid only for a limited amount of time. Nevertheless, it seems to be unjust in the commutative sense that a community whose traditional knowledge provided the idea to use a specific plant for the development of a successful product should go away empty-handed. ABS as established in the CBD and the NP is a tool to compensate the providers of traditional knowledge for their active contributions with or without reference to the patent system.

An objection that was brought forward against the moral justification of intellectual property rights for traditional knowledge might also be applied against ABS. Adapted to our context, the argument says that if required to share benefits with indigenous communities for the utilization of their traditional knowledge, then as a matter of consistency the traditional knowledge of 'Western' cultures would have to be rewarded too. Therefore, the critics suggest, all types of traditional knowledge should be considered to be common property (Anwander, Bachmann, Rippe, \& Schaber, 2002: pp96-97). A system that requires benefit sharing for all Western traditions would indeed be impracticable. The biopiracy examples mentioned above differ, however, from cases where companies in industrialized states produce products based on traditional knowledge from their own countries. As an example, let us think of the utilization of the traditional knowledge about the anti cold effect of Alpine herbs for the industrial production of herb candy or medical treatments against coughing. The utilization of this knowledge can be seen as part of the general development within 'Western' culture, from which also the community that provided the knowledge profits at least indirectly. Members of Alpine communities can profit from the candy and anti cold drugs and from the general lifestyle achievable in industrialized states. In this case, at least the nonmonetary benefit sharing with the traditional community is thus part of the general development of the product. In contrast, indigenous knowledge about Hoodia or the Neem tree was transferred from the indigenous people to the 'Western' culture. Some actors made (or are expected to make) financial profits from this knowledge; whereas, the traditional communities neither received any direct financial profits nor enjoyed the general lifestyle to which they contributed their knowledge. Therefore, it seems to be 
unfair to regard their traditional knowledge as 'common property'. It is another question for how long and to what extent a community should be compensated for a specific case of traditional knowledge. At some point the community may have been compensated sufficiently for providing this knowledge and it may be legitimate to consider the medical effect of the plant in question as common knowledge. Based on the same reflections, the 'compensation rights' warranted by patents expire after 20 years.

If my discussion of these cases is correct, reference to commutative justice can thus legitimize ABS with indigenous communities that provided traditional knowledge, because these communities must be compensated for their active contribution to the final product. In a similar vein, providing access to traditional crops or other domesticated plants or animals amounts to active contribution to the final product. In these cases, genetic resources are not a classical type of natural resource since they have been shaped by human invention and work for which commutative justice requests compensation.

The question that follows this conclusion concerns cases in which no traditional knowledge or active contribution by local breeders is involved. Can the entitlement to benefits for providing access to natural genetic resources growing within the territory of a state also be classified as an active contribution to the final product? If 'active contribution' is understood as intellectual or manual participation, which is the theory underlying this argument, providing territorial access to genetic resources in itself cannot count as an active contribution. In these cases, the entitlement to a share of the benefits can thus not be morally justified with reference to the first scenario.

\section{Compensation for Passive Contribution}

The previous scenario described compensation claims that could justify ABS based on an active contribution in the production process. However, the exchange addressed by commutative justice could also concern a contribution without active involvement; for instance, by supplying raw material, tools or other auxiliary means. I am speaking of passive contribution in this context. The second scenario illustrates how commutative justice could request a share of the benefits of a product in exchange for passive contribution:

Scenario two: Compensation for passive contribution: Passive contribution to a production process can consist of supplying material that is required throughout the production process. If person A owns the raw material that person B uses to 
make a profitable product, or if A owns an instrument or other auxiliary means with which B generates a profitable product, person $\mathrm{A}$ is entitled to a share of the resulting benefits. Comparable to the first scenario, the success of the product was owed to a specific input by A and the fact that B took advantage of A's property made it more difficult for A to produce the same product (at the same time). The extent of these claims depends on the circumstances.

The supply of classical natural resources as raw material is a good example of passive contribution. The CBD and NP treat genetic resources as a type of natural resource. This is suggested by the NP's reference to the 'exercise of sovereign rights over natural resources' (NP article 6) and even more specifically when the CBD classifies 'genetic resources' as a type of biological resource (CBD article 2), which in turn are generally understood to be renewable but depletable natural resources (Paavola, 2008). However, can providing genetic resources count as a passive contribution analogous to supplying biological raw material such as timber?

\section{Genetic Resources as a Special Type of Natural Resource}

It is characteristic that a constant supply of the natural resource in question is requested for the manufacturing process. If genetic resources belong to the category of natural resources in the classical sense, we expect that a constant supply of organisms carrying the requested genes from the country of origin would be required. Let us assume that a pharmaceutical company has performed a prospecting project in the rainforest of another country. In this project a biological compound derived from a plant was discovered to have an antibiotic effect. The company thus plans to produce a new type of antibiotic drug, let us call it 'NO BUG', based on this biological compound. The company will certainly try to use a method that does not depend on a constant supply of the respective plant from its natural habitat. Strategies include first, growing the plant in cultures, which are likely not located in the country of origin but at a place convenient for the company. Second, producers will try to avoid extracting the compound of interest from plants by manufacturing the product using genetically modified organisms or, as a third strategy, they will try to produce the compound by chemical synthesis. These strategies do not depend on a constant supply from the country of origin. The genetic resources obtained from this country can thus not be understood as the raw material of the resulting product. Instead, the original natural organism that was discovered in the country of origin could be regarded as a natural inspiration or instruction towards the 
final product. If genetically modified organisms are used, the genetic sequence is the valuable information; in the case of chemical synthesis it is the structure or composition of the useful compound. If this inspirational or instructive function of genetic resources cannot count as raw material, should it then be classified as auxiliary means or a tool for production? In order to address this question it may be helpful to think of other examples in which natural resources serve as auxiliary means. Fossil fuels could, for instance, be assigned to this category. Although petroleum can also serve as a raw material, for example, for the production of plastics, it serves as an auxiliary means if it is used to provide energy. How do these examples relate to genetic resources? Let us go back to the hypothetical drug NO BUG, of which we assume that the pharmaceutical company produces the key compound by chemical synthesis. Unlike petroleum as an auxiliary means, this chemical synthesis does not require any material samples from the original plant. In contrast to a machine, which, even though not consumed, is still required throughout the production process, the plant (the genetic resource in this example) is not requested during production. Instead, it provided the biochemical information necessary to produce the antibiotic NO BUG. Rather than being a type of raw material or auxiliary means or a tool, genetic resources thus seem to be a source of information, or, in other words, forms of non-material, informational natural resources. ${ }^{4}$ A significant difference in the resource-product relation of genetic resources compared to other types of natural resources has thus been detected. Bram De Jonge argues that due to this particular informational nature, genetic resources are non-rival in the sense that everybody can profit from them independently whether or not others have used them before. He suggests it is exactly because of this property that it is particularly important to ensure that a fair exchange occurs between the two parties, which is one of the aims of ABS (De Jonge, 2011). De Jonge seems to focus mainly on cases involving traditional knowledge or active contribution by local breeders. In these cases, compensation claims based on the first scenario are involved. However, at this place in the essay I examine genetic resources as natural resources without any particular contribution by the donor. ${ }^{5}$

\footnotetext{
${ }^{4}$ In the case of growing natural plants in culture, the interpretation of the original organisms as information may be a bit more far-fetched, but it can be understood as the information stored in seeds. Even in these cases, the plant-supply is usually not bound to the country of origin, because 'the information' can be used to grow and multiply the raw material elsewhere.

${ }^{5}$ For some additional reflections on the rival / non-rival nature of genetic resources, see, also footnote 10.
} 
This section suggested that contributing genetic resources could not count as a passive contribution in the sense of supplying material. However, there is a possibility that contributing a non-material natural resource could also trigger compensation claims based on commutative justice. This could be a passive contribution comparable to a situation where someone supplies a central piece of information that was not accessible to others but that is not dependent on any intellectual input by the supplier. Who could make such a contribution in the context of genetic resources? Two possible answers could be given: either the owner of the genetic resources or the holder of the sovereign rights over these resources.

\section{Ownership of Genetic Resources}

This section addresses the question of whether states that enter ABS negotiations, as suggested by the NP, can count as the owners of the genetic resources with morally legitimate property claims.

As mentioned above, in most cases, genetic resources can be understood as nonmaterial informative means towards production. ${ }^{6}$ Property-rights for non-material information are known as intellectual property rights. However, these rights are bound to intellectual contribution and thus fall into the category discussed in the previous section. Natural information has been discovered rather than invented. This puts into question the claim that natural genetic information should be subject to intellectual property rights (Anwander et al., 2002: pp 53-63; Nuffield council, 2002). Moreover, one may wonder, why the state on whose territory the information was discovered should be entitled to particular property rights, since information is not bound to any territory. This also holds for information that is carried by tokens of living organisms. In many cases, these organisms may have invaded the region, in which they were found. Samples of the organism may be found in ex situ collections. What binds the genetic information to the state, in which it was originally found? It is not even bound to the individual organism. DNA can be extracted, multiplied and distributed in the form of chemical extracts. Thanks to ongoing technological progress, the DNA sequence of more and more organisms is known and kept in non-material, abstract form. Besides genetic information, another example of the utilization of natural information is biomimetics. Biomimetics stands for the inspiration to enhance technological innovations by shapes

\footnotetext{
6 The idea that the very first resource organism that was used to collect the genetic information may have been material state-property will be discussed in the next section 'compensation for assistance'.
} 
or mechanisms in nature; this often-used type of natural information has always been considered to be openly available. States, in which the respective organisms can be found, are not considered to be entitled to participate in the benefit sharing from the utilization of this information. Why should genetic information be treated differently from the information used in biomimetics?

The characterisation of genetic resources as natural, informational and as detached from the territory in which they were found thus suggests that there cannot be any legitimate property rights over natural genetic resources. ${ }^{7}$ This leaves us with the question of whether instead of property rights state sovereignty might serve as a foundation for compensation claims in exchange for contributing genetic resources.

\section{State Sovereignty over Genetic Resources}

The CBD and its NP apply the concept of state sovereignty over natural resources to genetic resources (CBD articles 3, 15, NP article 6). However, in spite of its legal significance, the moral legitimation of state sovereignty over natural resources is not straightforward and has been critically discussed by different authors. ${ }^{8}$ Even if the concept of state sovereignty over material natural resources is accepted, it cannot be directly extended to genetic resources. Claims to the benefits from the use of genetic resources drawing from state sovereignty are based on an understanding of resource rights as territorial rights. This essay tried to establish, though, that in the case of genetic resources, the actual resource is a type of information, which is not bound to any territory, and over which it thus seems to be difficult to establish territorial rights. Only a small sample of territory-bound biological material is required. Moreover, Baruch Brody criticizes that the extension of the concept of 'state sovereignty over natural resources' to genetic resources applies the concept to the utilization of genetic information abstracted from the biological material outside the 'sovereign' country of origin. This extension goes beyond the usual sphere of influence of state sovereignty (Brody, 2010).

This paragraph thus suggests that an interpretation of state sovereignty over genetic resources that understands the state as the donor of immaterial informational

\footnotetext{
7 This argument does not hold for crops that were cultivated by selective breeding. As discussed in context of the previous scenario, cultivated crops have been shaped by humans; I would thus not count them as examples of natural resources.

${ }^{8}$ See for instance (Armstrong, 2014; Schuppert, 2014).
} 
genetic resources with compensation claims based on commutative justice is highly problematic.

If the arguments in this chapter are correct, passive contribution in the context of genetic resources is an inapplicable scenario because genetic resources are incomparable to raw material of which a constant supply is requested. Moreover, due to their informational, non-material and non-territorial nature, neither owners nor holders of state sovereignty can count as contributors of genetic resources in an exchange process. Therefore, reference to the scenario of passive contribution cannot justify moral claims to a share of the benefits derived from genetic resources for provider states. In the preceding section of this article, it was suggested that only in cases involving traditional knowledge or contribution by local breeders, can benefit sharing be justified by referring to an active contribution. I thus conclude that a state that simply provides access to the natural genetic resources growing on its territory does not have compensation claims based on a direct contribution to the success of the product. Nevertheless, a state that allows a company or research institution to enter stateterritory in order to study or collect biological material seems to have claims to compensation for this gesture. These claims and their relation to ABS in the CBD and NP are addressed with the next section.

\section{Compensation for Assistance}

If state sovereignty over genetic resources does not mean that the state is the contributor of the genetic resources, how else could it be understood? 'State sovereignty' could be interpreted -as implied by Brody (Brody, 2010)- to stand for the territorial right to self-determination. This includes the right to control entry into state territory and actions that take place within that territory. If a state with this right allows companies or research groups to enter its biodiversity-rich territory in order to study or collect biological material, this is a form of cooperation and assistance. As a matter of commutative justice, the state providing access should get something in return for this assistance. This idea is exemplified by the third scenario:

Scenario three: Compensation for assistance: This is a type of return service for a short and small involvement that does not amount to a contribution. Person A gives person B a useful hint or helps B in a situation. If A and B are, for instance, in a commercial relationship, this type of assistance justifies compensation adapted to the size of the favour. Assistance of this kind could consist in lending 
property in an emergency situation, but unlike the case of passive contribution, this assistance is of short duration. It is not required as a constant condition for the profitable enterprise. In comparison to active contribution, assistance is less significant, innovative and path-breaking.

As indicated above, this essay deals with the question of what providers of genetic resources are entitled to be compensated for in the context of ABS in the CBD and its NP. Such a substantive understanding of commutative justice entails the difficulty of confronting the incommensurable offers made by the two parties involved in the exchange. It is certainly not the aim of this study to make any general suggestions as to how to determine appropriate compensations in such cases. However, the NP makes some rather substantive suggestions concerning the benefits that might be offered and thereby sets some standards for ABS negotiations. It is thus important to put these suggestions in relation to what is being offered by the biodiversity-rich side in the exchange. In the previous sections of this essay it has been suggested that, if no traditional knowledge or active contribution by local breeders is involved, the offer is simply a one-time access to a territory with the permission to collect a specific type of information. However, it might be countered that in order to be able to extract this information some biological material must be removed, and that even if the genetic information is not the property of the providing state, the removed material may be. Even if it is taken into account that such a biological sample may be the property of the state of origin, it is still questionable whether providing one-time access to such a sample justifies the rather extensive requests for various payments, joined ownership in property rights and various non-monetary benefits listed in the Nagoya Protocol. The insight that these benefits are offered in the exchange for assistance and not for any active or passive contribution seems to require reconsideration of benefit-claims.

Finally, independent of the extent of the benefits, one may wonder whether it is fair to bind compensation for providing access to state-territory to the success of the industrial project, for which access has been granted. If the answer to this question were negative, at least some of the benefits suggested by the NP require reconsideration.

\section{Compensation for Compliance with a Request}

If my argument hitherto is correct, it may surprise many that the NP has been signed and ratified by a large number of states. I will argue that this broad approval of the NP is based on the aim of providing commutative justice at another level; namely, to 
compensate those countries that conserve biodiversity for complying with the request by the international community. Rather than offering a share of the benefits in return for providing access to genetic resources, commutative justice so understood, demands the possibility to profit from the ABS system in return for the commitment to conserve biodiversity. ${ }^{9}$ The basic idea of such a justification scenario is the following:

Scenario four: Compensation for compliance with a request: People who follow requests made by others may be entitled to compensation. If person A exerts time and energy to fulfil the request made by person B of cleaning the building in which person B generates a product, person A should be compensated for this work. The size of this compensation should not depend on whether the product can be sold or not, since compensation is paid for complying with the request in question. Unless this request is directly linked to the success of the product (e.g. a request for advertising), it can be fulfilled and thus results in entitlements, independently of how the product sells.

So far, the discussion of the NP in this essay has omitted a central aspect of the protocol, namely its integration in the CBD. As mentioned in the beginning, the NP specifies one of the three major objectives of the CBD. The other two objectives are: 1) the conservation of biological diversity and 2) the sustainable use of its components. This suggests that the request of ABS for genetic resources needs to be understood in the context of the other objectives. In that sense, biodiversity-rich states, which follow the request of the industrialized world to conserve biodiversity and make an effort towards sustainable development, are entitled to compensation. Due to its intuitive persuasiveness, not much space will be lost here to argue in favour of this claim. Instead, the essay examines whether an ABS system is a fair means to address it.

One problem with ABS in this respect is that benefits are available only for those states in which companies or research teams wish to access biodiversity. Furthermore, some of the suggested benefits such as payment of royalties or licence fees only result in profit if the user was successful in developing a lucrative product from the genetic resource in question. Such success-related benefits seem to be justified in exchange for an active or passive contribution since the quality of the contribution is a factor deciding the extent of success. However, as compensation for compliance with a request that does

\footnotetext{
${ }^{9}$ The idea that the NP should compensate biodiversity-rich states for conserving biodiversity also played a role in the negotiations of the NP (Oberthür \& Rosendal, 2013; Wallbott, Wolff, \& Pozarowska, 2013)
} 
not concern the production process itself, these success-related benefits are problematic. If the purpose of the third objective of the CBD is to compensate states for fulfilling their commitment to biodiversity conservation and sustainable development, the same compensation should be granted to all states that make similar efforts. This should be independent of whether a company launches any projects involving genetic resources of that country and even more independent of the success of such projects. As it is, the third objective of the CBD favours states with dense occurrence of biodiversity, which is particularly interesting for companies that search for potent natural compounds. Conservation of biodiversity is, however, also important in commercially less promising areas, for instance in deserts, which also contain endangered species and are of high ecological, aesthetic, instrumental or other value. Moreover, the fact that some type of project is being performed in one state may render another state with a similar biodiversity profile less interesting for companies that wish to undergo a comparable project. In such a case, only one state could profit from benefits, even though all of them are expected to conserve and protect biodiversity. ${ }^{10}$ Finally, the ABS system favours states with governments focusing on relations with industry and research institutions rather than those focusing on conservation projects. An ABS system thus seems not to be a fair compensation for compliance with the request for biodiversity conservation.

A more pragmatic than moral argument in favour of using ABS as a compensation for conserving biodiversity suggests that it could provide an incentive to protect biodiversity. If, however, opportunities for benefits through this system turn out to be lower than expected, this may reduce the motivation to conserve biodiversity. Disappointment with respect to the potential magnitude of benefits may be caused by disproportionate expectations that were associated with bioprospecting projects in the 1990s, when the CBD was ratified. In the meantime, the paradigm example of ABS between the industrial company Merck and Costa Rica's National Biodiversity Institut INbio was abandoned without the discovery of any new rewarding pharmaceutical (Conniff, 2012). This example illustrates that the road from a potentially promising

\footnotetext{
10 In that sense, and in contrast to De Jonge's observation (De Jonge, 2011), genetic resources are even more rival or excludable than material types of natural resources, where all states with incidences of the resource in question can profit from the demand created by the first user. Joseph Millum refers to the same point when he notices that the sale of the information entailed in the genetic resources on the land of one landowner reduces the value of the same genetic resource on the land of others (Millum, 2010).
} 
natural compound to a pharmaceutical blockbuster is longer and success in this development probably less frequent than envisioned.

Another problem when using ABS as a compensation mechanism for compliance with the request of conserving biodiversity concerns the contract partners, which act at different levels. Partners in the ABS negotiations are usually representatives of the biodiversity-providing country on the one side, and research institutions or companies interested in utilizing biodiversity on the other side. In contrast, it is the international community that requests conservation of biodiversity and sustainable development in the CBD and NP. Using the ABS as compensation shifts the responsibility to compensate states for complying with the international community's requests to research institutions and companies, which are not the actors who made these requests. This is not to say that companies who profit from genetic resources should be discharged from any environmental responsibility, but this is not directly related to the duty of compensating states that comply with requests of the international community.

In sum, the application of the fourth scenario to the context of ABS in the CBD and its NP concerns a different type of exchange other than the application of the previous scenarios. Rather than justifying claims to benefits in return for providing access to genetic resources, the fourth scenario has been applied to explain claims from biodiversity-rich states to be compensated for complying with the requests set forth in objectives 1 and 2 of the CBD. These seem to be valid claims based on commutative justice. However, the ABS system seems to be an unfair means to address them because it only compensates a subgroup of those who comply with the requests in question.

\section{A Brief Excurse to Other Justice Arguments for ABS}

The presented analysis of ABS in the CBD and its NP from the point of view of substantial commutative justice may trigger responses that touch other justice dimensions. This chapter will briefly address some of these arguments. However, I will not be able to address these topics in detail and do not wish to make any general conclusion as to whether ABS is an appropriate tool to promote justice in the noncommutative sense.

\section{Reparative Justice}

As mentioned before, some authors discuss reparative justice as a type of commutative justice because it also concerns a type of exchange albeit with the particularity that 
compensation is paid in exchange for something that happened in the past. ${ }^{11}$ The ABS system has mainly been requested by developing states often with a colonial past. It is well known that in the $16^{\text {th }}-20^{\text {th }}$ century, colonial regimes not only promulgated domination and suppression of the inhabitants of colonized nations (which included many biodiversity-rich states) but also the exploitation of their natural resources. The colonial rulers profited from valuable land, lumber, gems or ores and in addition from indigenous labour. Generally, the colonies did not get a fair share of the benefits derived from their resources. It could thus be argued that benefits paid by utilizers of genetic resources to biodiversity-rich states are justified as reparation for historical wrongs that the latter have suffered. Even today, developing states are economically and politically highly dependent on industrialized nations, a situation, which is described as 'Neocolonialism'. The CBD and its NP could be understood as a tool to fight this type of injustice. Many of the biodiversity-rich states that would profit from ABS have indisputably suffered serious injustices from the colonial and neo-colonial systems. However, reparation for these wrongs should be paid to all and not only to those that are rich in biodiversity and can provide access to genetic resources. Therefore, ABS in the CBD and its NP is neither a fair means to pay reparation for colonial nor for neocolonial injustices because not all states that have claims to reparation can profit from this system.

\section{Justice towards Indigenous and Local Communities}

When the concept of commutative justice was introduced in this article, I mentioned the procedural Roman Law interpretation of commutative justice, which requires that both parties agree on a transaction. With Prior Informed Consent (PIC) and Mutually Agreed Terms (MAC) the CBD and its NP suggested two tools that should ensure commutative justice in the procedural sense in ABS negotiations. The implementation of these procedures raises the questions of who the involved parties should be and how they can be fairly integrated into the process. As international treaties, the CBD and NP proceed from the assumption of the sovereign states as the involved parties. However, the CBD and NP also emphasize that indigenous and local communities should be considered.

\footnotetext{
11 This understanding can be traced back to Thomas Aquinas' interpretation of Aristotle. As mentioned

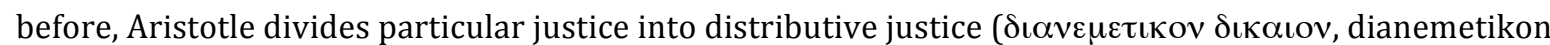

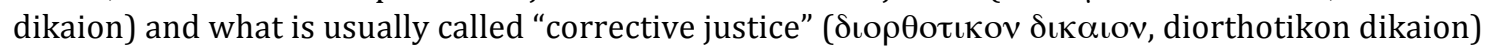
(Aristotle, 1992: Book V). In his interpretation of Aristotle, Thomas Aquinas opposes distributive justice (iustitia distributiva) to commutative justice (iustitia commutativa), in which he includes reparation as well as e.g. commercial exchange (Aquinas, 1993: II-II, Q61).
} 
The NP has been the first international treaty that explicitly notes the UN Declaration on the Rights of Indigenous Peoples (Greiber et al., 2012: p55; Tobin, 2013), and it highlights that indigenous and local people should be involved in MAT and PIC processes. The principle of Free Prior Informed Consent (FPIC), which is usually treated as a synonym for PIC, is an established tool for interaction with minorities (Pillay, 2013). It should be noted, though, that when the NP states that parties shall consider indigenous and local communities, qualifying language is applied. For instance, in articles $5,6,7,12$, this request is complemented by the phrase "in accordance with domestic law, each party shall [...]" or articles 11,12 request that "each party shall endeavour [...], as appropriate [...]." Such language leaves room for an interpretation that the respective national government can decide to what extent indigenous and local communities are involved in the process (Greiber et al., 2012: p100; Tobin, 2013). As this is not directly a question of commutative justice but rather of recognition justice or participatory justice, it would go beyond the scope of this article to examine in detail whether the CBD and its NP are just in how they involve and respect indigenous and local communities.

\section{Distributive Justice}

Finally, I would like to add a few thoughts concerning the classical counterpart to commutative justice, namely distributive justice. In the literature on global justice, there is a broad discussion on how natural resources and benefits deriving from them should be distributed worldwide (e.g. Caney, 2001). In the context of genetic resources, the argument for a global distribution of at least some benefits can be supported by reference to their particular non-material informative nature, due to which genetic resources could be considered as a public and a common good (De Jonge, 2011). However, as discussed above, history has shown that making genetic resources freely available to actors in all states, de facto favoured Northern companies with more funds available to invest. As a result, people from the global North benefited from genetic resources, whereas those in the South ended up empty handed. Joseph Millum refers to distributive justice to argue for property rights over biodiversity, which, in turn, could legitimize ABS based on the second scenario described above. In that sense, he combines aims and requirements of distributive and commutative justice. Millum speaks of a justification based on instrumental accounts, according to which underprivileged indigenous communities should have property rights over the areas of biodiversity that 
they occupy. He argues that this would be instrumental to achieve distributive justice (Millum, 2010). However, his approach towards distributive justice only improves the situation of those poor indigenous communities who occupy areas with a high incidence of biodiversity. Poverty in urban areas such as slums would not be affected by this approach. A more comprehensive approach that focuses on a more just and equal global distribution of benefits from genetic resources seems to be more effective as an instrument to achieve distributive justice rather than assigning property rights to certain disadvantaged communities. Distributive justice seems to request that the users of genetic resources share some of the benefits that they draw from natural genetic information with the rest of the world. In this sense, those who profit from genetic resources could for instance be asked to pay into a global fund, which could be employed for the common good.

\section{Conclusion}

This essay aimed at contributing to a critical discussion of ABS as a tool to promote commutative justice. For this purpose the essay addressed the question of what it is that providers of genetic resources are being compensated for. Potential compensationclaims have been exemplified using four general scenarios, which were derived from the text and context of the CBD and its NP. Although ABS is often understood as contributing towards commutative justice, the argumentation in this essay suggests that the notion that provider states have particular claims to genetic resources on their territory, and that they thus must be compensated whenever genetic resources are used, is highly problematic. However, the essay also argues that the international community does have moral duties to compensate those states, which comply with the requests set out in the first and second objective of the CBD. The setting of the ABS system as dealing with the third objective of the CBD indicates that it is understood as a compensation for biodiversity conservation. In this regard, this essay welcomes the support and ratification of the NP as an important step in recognizing these duties. Moreover, requests for biodiversity-conservation and the issue of dealing with benefits from genetic resources raise justice questions beyond the dimension of commutative justice. Again, it is an achievement that the NP triggers a discussion and raises the awareness of these issues. However, it is important that the ratifying parties are aware of the moral problems discussed in this essay and the risks associated with them. If the arguments brought forward in this essay are correct, the following three recommendations should 
be considered on the one hand, for the implementation of the Nagoya protocol into domestic legislation of ratifying states; on the other hand, in specific ABS negotiations:

First, the essay recommends that particular attention should be given to negotiations in which traditional knowledge or active contribution by local breeders is involved. These are the cases in which commutative justice in the classical sense requests compensation for the providers.

Second, in cases where providers of genetic resources simply allow the userparty to enter state territory in order to collect, for instance, a sample of a natural plant, modesty with respect to benefit-claims seems to be appropriate. This is particularly true for utilizers in non-commercial research, where excessive benefit-claims by provider states may hinder collaborations and harm research in providing as well as utilizing states.

Third, mechanisms should be introduced that allow those states that make an effort towards conservation of biodiversity and sustainable development to be compensated for this effort even if they are not involved in any ABS negotiations for genetic resources.

\section{Acknowledgements}

I would like to thank Peter Schaber and Fabian Schuppert for their repeated input and suggestions on how to improve earlier versions of the manuscript and Susette BiberKlemm as well as two anonymous reviewers for her helpful comments. This work was supported by the UZH Research Priority Program (URPP) on 'Global Change and Biodiversity'.

\section{References}

Anwander, N., Bachmann, A., Rippe, K. P., \& Schaber, P. (2002). Gene patentieren, Eine ethische Analyse. Paderborn: Mentis.

Aquinas, T. (1993). Summa Theologiae, Electronic Edition; trans. English Dominican Fathers. Charlottesville, Virginia, USA: InteLex Corp.

Aristotle. (1992). Nicomachean Ethics, Electronic Edition; trans. W.D. Ross. Charlottesville, Virginia, USA: InteLex Corp.

Armstrong, C. (2014). Against "permanent sovereignty" over natural resources. Politics Philosophy Economics, 1-23. doi:10.1177/1470594X14523080.

Beattie, A. J. (2005). New Products and Industries from Biodiversity. In Rashid M. Hassan, Robert Scholes, \& Neville Ash (Eds.), Ecosystms and Human Well-Being: Current State and Trends. Findings of the Condition and Trends Working Group. (pp. 273-295). London: Island Press.

Brody, B. A. (2010). Intellectual Property, State Sovereignty, and Biotechnology. Kennedy Institute of Ethics Journal, 20(1), 51-73.

Buck, M., \& Hamilton, C. (2011). The Nagoya Protocol on Access to Genetic Resources and the Fair and Equitable Sharing of Benefits Arising from their Utilization to 
the Convention on Biological Diversity. RECIEL, 20(1), 47-61. doi:10.1111/j.14679388.2011.00703.x

Caney, S. (2001). International Distributive Justice. Political Studies, 49, 974-997.

Conniff, R. (2012). A Bitter Pill. Conservation, 13,

http://conservationmagazine.org/2012/2003/a-bitter-pill/(accessed Sept 2016).

Dauda, B., \& Dierickx, K. (2013). Benefit sharing: an exploration on the contextual discourse of a changing concept. BMC Medical Ethics, 14(36), 1-8. doi:10.1186/1472-6939-14-36

De Jonge, B. (2011). What is Fair and Equitable Benefit-sharing? J. Agric Environ Ethics, 24, 127-146. doi:10.1007/s10806-010-9249-3

De Jonge, B., \& Korthals, M. (2006). Vicissitudes of Benefit Sharing of Crop Genetic Resources: Downstream and Upstream. Developing World Bioethics, 6(3), 144157. doi:10.1111/j.1471-8847.2006.00167.x

Greiber, T., Moreno, S. P., Ahren, M., Carrasco, J. N., Kamau, E. C., Medaglia, J. C., ... Perron-Welch, F. (2012). An Explanatory Guide to the Nagoya Protocol on Access and Benefit-sharing. IUCN Environmental Law Centre, Available at:

https://cmsdata.iucn.org/downloads/an_explanatory_guide_to_the_nagoya_prot ocol.pdf (accessed Sept 2016).

Kamau, E. C., Fedder, B., \& Winter, G. (2010). The Nagoya Protocol on Access to Genetic Resources and Benefit Sharing: What is new and what are the Implications for Provider and User Countries and the Scientific Community? LEAD, 6(3), 246-262.

Korthals, M., \& De Jonge, B. (2009). Two different ethical notions of benefit sharing of genetic resources and their implications for global development. New Genetics and Society, 28(1), 87-95. doi:10.1080/14636770802670308

Koslowski, P. (2001). Commutative Justice Principles of Ethical Economy (pp. 184-210): Springer.

Millum, J. (2010). How should the benefits of bioprospecting be shared? The Hastings Center report, 40(1), 24-33.

Nuffield Council on Bioethics (2002). The ethics of patenting DNA, a discussion paper. Available online at: http://nuffieldbioethics.org/wpcontent/uploads/2014/07/The-ethics-of-patenting-DNA-a-discussion-paper.pdf (accessed Sept 2016).

Oberthür, S., \& Rosendal, K. G. (2013). Global governance of genetic resources, Background and analytical framework. In S. Oberthür \& K. G. Rosendal (Eds.), Global Governance of Genetic Resources, Access and benefit sharing after the Nagoya Protocol (pp. 1-17). New York, London: Routledge.

Paavola, J. (2008). Resources. In William A. Darity (Ed.), International Encyclopediao of the Social Sciences (pp. 211-212). Michigan: Gale.

Pillay, N. (2013). Free, Prior and Informed Consent of Indigenous Peoples. available at http://www.ohchr.org/Documents/Issues/IPeoples/FreePriorandInformedCons ent.pdf (accessed Sept 2016).

Ritchie, D. G. (1894). Aristotle's Subdivisions of 'Particular Justice'. The Classical Review, $8(5), 185-192$.

Schroeder, D. (2006). Benefit Sharing: From Obscurity to Common Knowledge. Developing World Bioethics, 6(3), ii. doi:10.1111/j.1471-8847.2006.00176.x

Schroeder, D. (2007). Benefit sharing: it's time fr a definition. J MEd Ethics, 33, 205-209. doi:10.1136/jme.2006.016790

Schroeder, D., \& Pisupati, B. (2010). Ethics, Justice and the Convention on Biological Diversity. UNEP, availabla at 
http://www.unep.org/delc/Portals/119/UNEP_Justice_Final_V2a.pdf (accessed Sept 2016).

Schuppert, F. (2014). Beyond the national resource privilege: towards an International Court of the Environment. International Theory, 6(1), 68-97. doi:10.1017/S1752971913000262

Sheridan, C. (2005). EPO neem patent revocation revives biopiracy debate. Nature biotechnology, 23(5), 511-512. doi:10.1038/nbt0505-511

Stumpf, K. (2014). Reconstrutiong the 'biopiracy' debate from a justice perspective. In D. Lanzerath \& M. Friele (Eds.), Concepts and Values in Biodiversity (pp. 225-242). London, New Yorik: Routledge.

Tobin, B. M. (2013). Bridging the Nagoy Compliance Gap: The Fundamental Role of Customary Law in Protection of Indigenous Peoples' Resource and Knowledge Rights. Law, Environment and Developmen Journal, 9(2), 142-162.

UN. (1992). Convention on Biodiversity (CBD). Available at http://www.cbd.int/convention/text/ (accessed Sept 2016).

UN. (2010). Nagoya Protocol on Access to Genetic Resources and the Fair and Equitable Sharing of Benefits Arising from their Utilization to the Convention on Biological Diversity. Availabla at http://www.cbd.int/abs/doc/protocol/nagoya-protocolen.pdf (accessed Sept 2016).

Wallbott, L., Wolff, F., \& Pozarowska, J. (2013). The negotiations of the NAgoya Protocol, Issues, coalitions and processes. In S. Oberthür \& K. G. Rosendal (Eds.), Global Governance of Genetic Resources, Access and benefit sharing after the Nagoya Protocol (pp. 33-59). New York, London: Routledge.

Wynberg, R. (2005). Rhetoric, Realism and Benefit-Sharing, Use of Treditional Knowledge of Hoodia Species in the Development of an Appetite Suppressant. The Journal of World Intellectual Property, 7(6), 851-876. doi:10.1111/j.17471796.2004.tb00231.x 